\title{
EDAX - More Than 50 Years of Influence On Microanalysis
}

\author{
Patrick Camus ${ }^{1}$ and Tara Nylese ${ }^{1}$
}

${ }^{1 .}$ EDAX Inc., A Division of Ametek, 91 McKee Place, Mahwah, NJ 07430

The history of EDAX actually pre-dates electron beam microanalysis. The predecessor of EDAX, Nuclear Diodes Inc., was founded in 1962 by Charles Walsh (President) and Alan Sandborg (VicePresident and detector expert) in Prairie View, IL.

Nuclear Diodes Inc. was renamed as EDAX International in 1972. This was a good choice as the name has been synonymous with EDS microanalysis ever since. The company was later purchased by Philips in 1974. Alan Devenish was named President in 1978, Figure 1, and expanded the company significantly. He was promoted to higher positions within the company until he retired in 2010. The factory was moved to its current location in Mahwah, NJ in 1988. EDAX was purchased by AMETEK in 2001, but still retains its historical corporate identity.

Charlie W. wanted to start a company making solid state radiation detectors. These detectors, made from Silicon, were just beginning to be used in Nuclear Physics experiments at the National laboratories around the country. He wanted to get in early on their commercial development.

Alan S. actually was Employee \#1 and officially retired in 2013 with more than 50 years of tenure, Figure 2. He is still active in the field of microanalysis through consulting. They made Silicon Surface Barrier Detectors for nuclear research applications; alpha and beta ray detection. Their biggest competitor was Ortec, now an Ametek company. He was instrumental in developing the early technologies, many covered by patents, that would eventually turn into the x-ray instrumentation that we take for granted today. These include developing the silicon surface barrier, Lithium diffusion methods for both Silicon and Germanium detectors, and liquid nitrogen cooled detectors.

Developments continued throughout the years for both hardware and software innovations. In 1964, liquid nitrogen cooling was added to detectors. Around this time, Ge(Li) detectors were developed for gamma ray detection, followed by $\mathrm{Si}(\mathrm{Li})$ detectors. In 1969, after the creation of an electronics group, the Nuclear Diodes 505 was released as the first commercially available x-ray system for EM, Figure 3. In addition, the first X-ray source EDXRF was introduced.

In 1972, the first windowless detector, ECON, was released which set the standard for low-energy detection for a decade. In 1972, the EDXRF system, EXAM, was released. That same year, EPIC, a microprocessor-based peak identification system was introduced. In 1973, WEDAX was released that combined EDS with WDS spectrometer automation. In 1978, the PV9100 EDS x-ray microanalysis system was released with a color display on a DEC mini computer.

In 1992, DX-4 was the world's first Windows based EDS system. In 1995, the CryoSpec was released as the first LN-free Si(Li) detector. In 1996, Sapphire detectors provided best standard resolution of any EDS detectors.

In 2002, the Polaris was the first commercial microcalorimeter EDS detector. In 2002, the MegaSpec Silicon Drift Detector was released. In 2007, an updated Apollo SDD was released. In 2011, the Apollo XLT SDD for TEM was released. In 2014, the Element SDD with a Si-N window was released. In 2016, the Elite Super SDD with Si-N window was released. 
EDAX has been very influential from the very beginnings of EDS microanalysis in pushing the technology to make the hardware and software more capable and more useful for users of all electron microscopes.

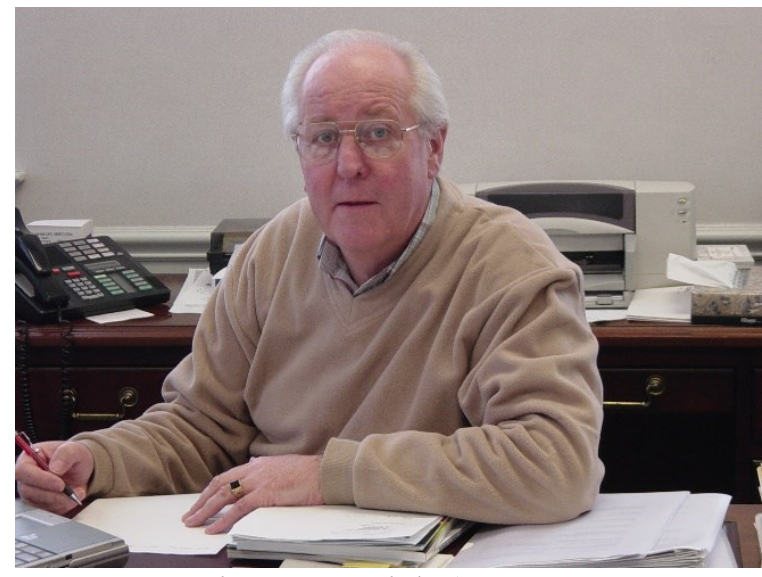

Figure 1. Alan Devenish (EDAX: 1978-

2010)
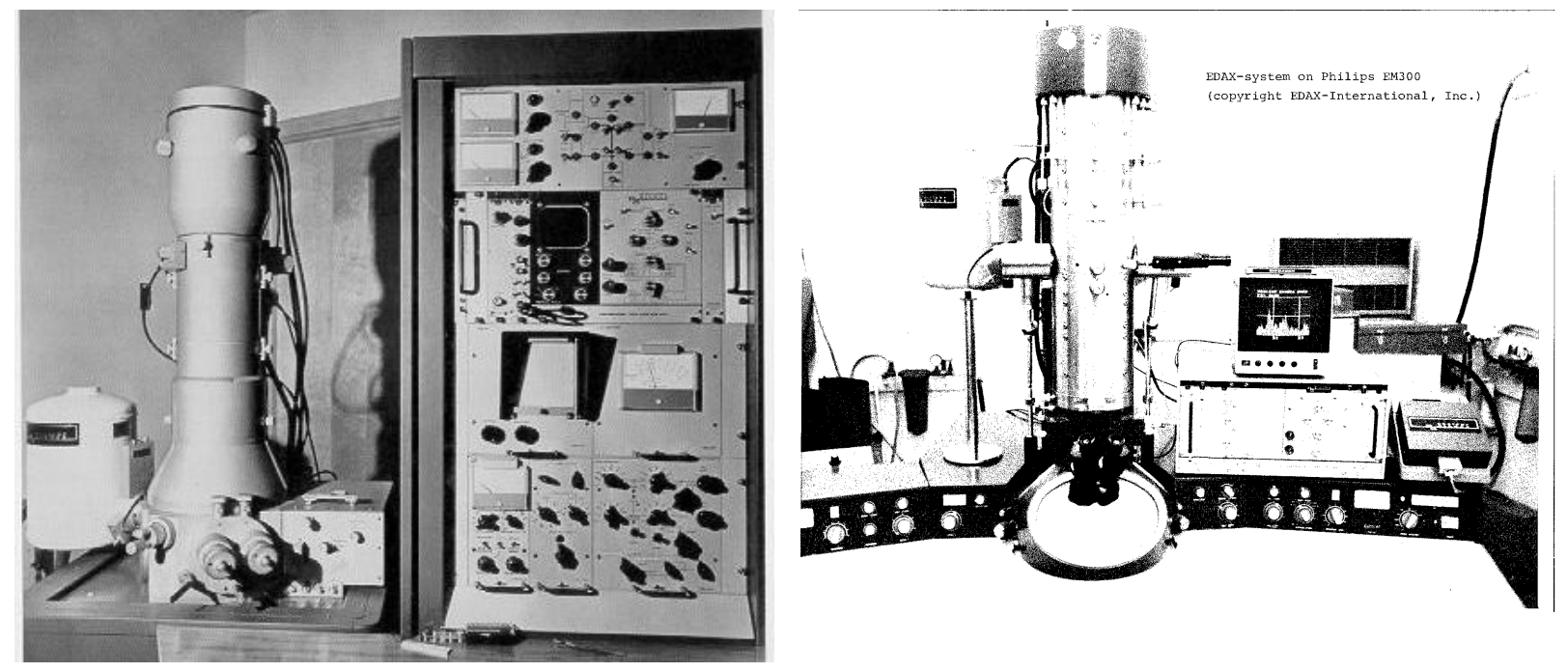

Figure 3. a) Pre-1973 Nuclear Diodes EDS system on a Cambridge SEM, b) Pre-1973 Nuclear Diodes EDS System on Philips EM300.

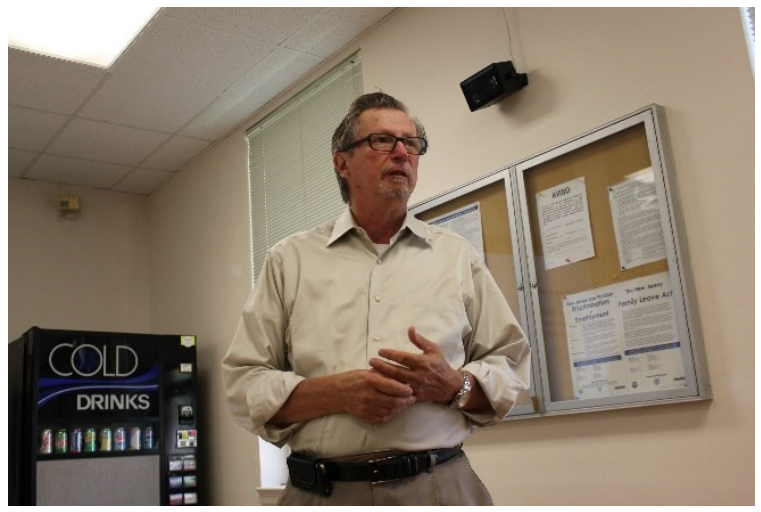

Figure 2. Alan Sandborg (Nuclear

Diodes/EDAX: 1962-2013) 